\title{
Calls for independent inquiry into bombing
}

$\mathrm{T}$ hree weeks after the United States' bombing of a hospital operated by medical humanitarian group Médecins Sans Frontières (MSF) in Kunduz, Afghanistan, the death toll is mounting along with international pressure for an independent investigation.

MSF now confirms at least 30 people were killed in the Oct. 3 attack including 10 patients, 13 staff and 7 unrecognizable bodies. A further 27 MSF staff and an unknown number of patients and others were also injured.

The United States, Afghanistan and the North Atlantic Treaty Organization (NATO) have launched internal investigations into why the hospital was targeted without warning, despite being known to all fighting parties in the region and protected under international humanitarian law.

Given that the attack may be a war crime, MSF and leading medical organizations are also demanding an independent inquiry by the International Humanitarian Fact-Finding Commission.

"We need to understand with absolute clarity what happened, how it happened and why in order to truly reaffirm international humanitarian law and the protection of medical facilities," says Stephen Cornish, executive director of MSF Canada. "Unfortunately, we've had no indication from the Afghan or US governments of their willingness to accept an independent investigation."

International support for an impartial inquiry is growing. Over 327000 people have signed a petition urging the Obama administration to submit to outside investigation. Delegates from some 60 national medical groups at the World Medical Association's General Assembly on Oct. 17 called for "immediate enquiry into the attack by an independent body and the assumption of responsibilities" by US and Afghan officials.

Canada's doctors strongly support the resolution, says Canadian Medical Association President Dr. Cindy Forbes.

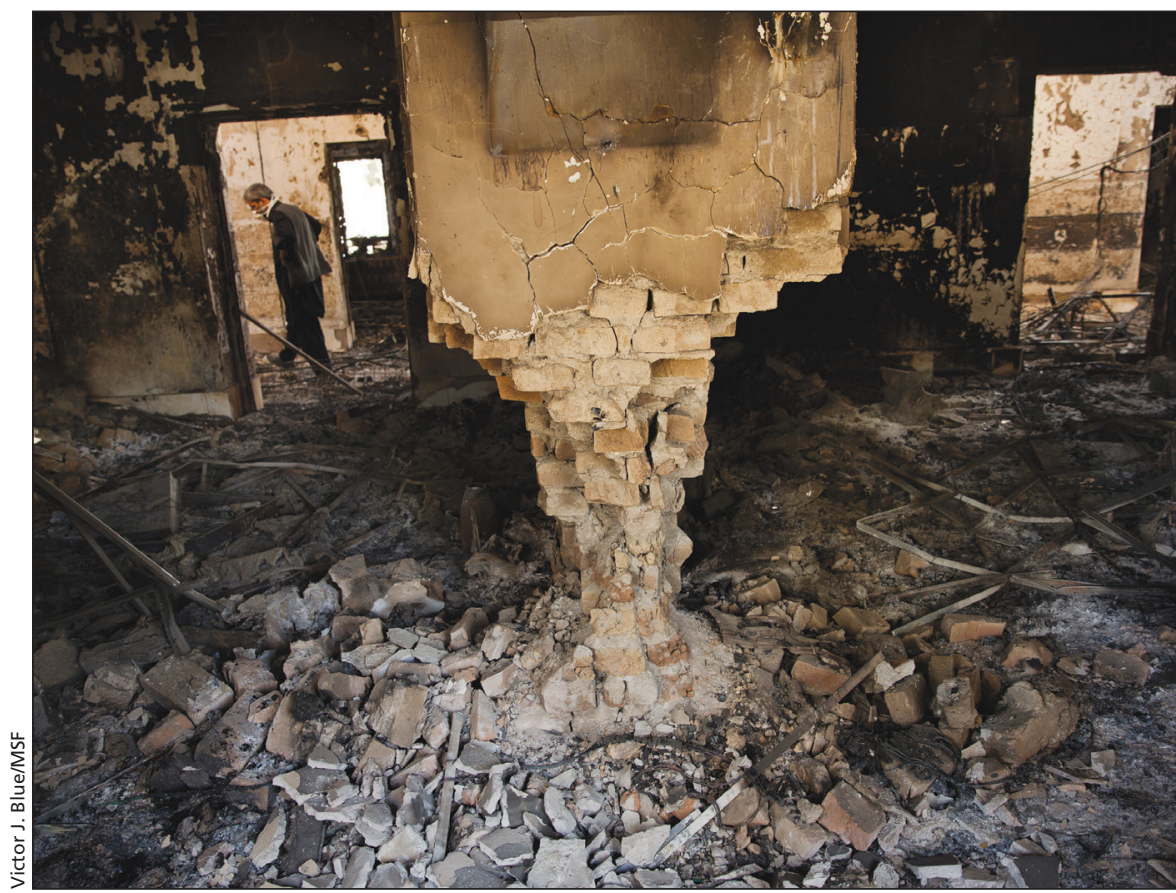

A man wearing a surgical mask walks among debris in the damaged Médecins Sans Frontières Trauma Centre in Kunduz, northern Afghanistan.

"There needs to be some comfort going into the future that these events are looked at independently," she says. Otherwise, "it may deter some people from going into these areas where their help is so badly needed."

Confidence in the ongoing US, Afghan and NATO investigations has been shaken in past weeks by military officials' shifting and conflicting accounts of the bombing. US officials first described the attack as "collateral damage" from an air strike called by their troops nearby, then as a "mistake" called in by Afghan troops. By other accounts, the US intended to "clear the trauma center" believing it was under Taliban control. Afghan officials have maintained that the Taliban was firing on their forces from the hospital grounds.

MSF absolutely denounces these claims, says Cornish. "No one reported any such incursions or any type of fighting." Even if Taliban forces were present, "there should have been advance warning of eminent risk to patients and the medical facility, which wasn't received."

Cornish also dismisses theories that the hospital wasn't the intended target of the attack. "We saw repeated, targeted attacks over an hour, focusing on the nucleus of the hospital - the emergency room, the intensive care unit and leaving the surrounding compound completely untouched."

Now, the future of MSF's operations in the area hangs in the balance. "Hundreds of thousands of people in north-eastern Afghanistan have lost the only life- and limb-saving surgery that was available at a time when conflict is raging all around them," says Cornish. "We can't rebuild and restore the facility until we understand why this tragedy happened and have guarantees that such an event will not reoccur." Lauren Vogel, CMAJ

CMAJ 2015. DOI:10.1503/cmaj.109-5189 